\title{
ИЗ ИСТОРИИ МОДАЛЬНОГО АНАЛИЗА И СТЕРЕОЛОГИИ В ПЕТРОГРАФИИ
}

\section{Войтеховский Ю.Л.}

Геологический институт КНЦРАН, Anamumbl,woyt@geoksc.apatity.ru

Количественный минералогический (модальный) анализ горных пород и руд в шлифах -фундаментальный метод минералогии (в том числе технологической), петрографии (в классификации магматических и метаморфических горных пород и петрологических реконструкциях) и литологии (то есть петрографии осадочных горных пород). Его строгое обоснование имеет принципиальное значение. В первую очередь подчеркнём, что соотношения Делесса $\mathrm{dV}_{\mathrm{i}}=\mathrm{dS} \mathrm{S}_{\mathrm{i}}$ [1], Розиваля $\mathrm{dS}_{\mathrm{i}}$ $=\mathrm{dL}_{\mathrm{i}}$ [2] и Глаголева $\mathrm{dL}_{\mathrm{i}}=\mathrm{dN}_{\mathrm{i}}[3-5]$, последовательно понижающие размерность пространства предельно элементарными соотношениями (а именно, приравнивающие объёмные доли минеральных фаз к площадным, площадные - к линейным, линейные - к точечным), не имеют отношения к геометрическому принципу Кавальери: $\mathrm{S}_{1 \mathrm{i}}=\mathrm{S}_{2 \mathrm{i}} \rightarrow \mathrm{V}_{1}=\mathrm{V}_{2}$ - если площади всех как угодно близких параллельных сечений двух тел попарно равны, то их объёмы тоже равны (рис. 1).

В современных обозначениях этот принцип, исторически предшествовавший интегральному исчислению, имеет ясный смысл: $\mathrm{V}_{1}=\int \mathrm{S}(\mathrm{z}) \mathrm{dz}=\mathrm{V}_{2}$, где $\mathrm{S}(\mathrm{z})$ - непрерывная функция изменения площадной доли некоторой минеральной фазы вдоль оси $\mathrm{Z}$, нормальной к сечениям. Но модальный анализ горных пород и руд в шлифах, сводящийся к накоплению статистик площадных, линейных или точечных долей минеральных фаз от шлифа к шлифу, не использует процедуру интегрирования, а лишь ведёт к оценке их средних значений. При этом можно утверждать, что объём любой минеральной фазы в горной породе или руде заключён в пределах: $\mathrm{S}(\mathrm{z})_{\min } \Delta \mathrm{z}=\int \mathrm{S}(\mathrm{z})_{\min } \mathrm{dz}<\mathrm{V}<\int \mathrm{S}(\mathrm{z})$ $\max _{\mathrm{m}} \mathrm{dz}=\mathrm{S}(\mathrm{z})_{\max } \Delta \mathrm{z}$, где $\Delta \mathrm{z}-$ толщина изучаемого образца горной породы.

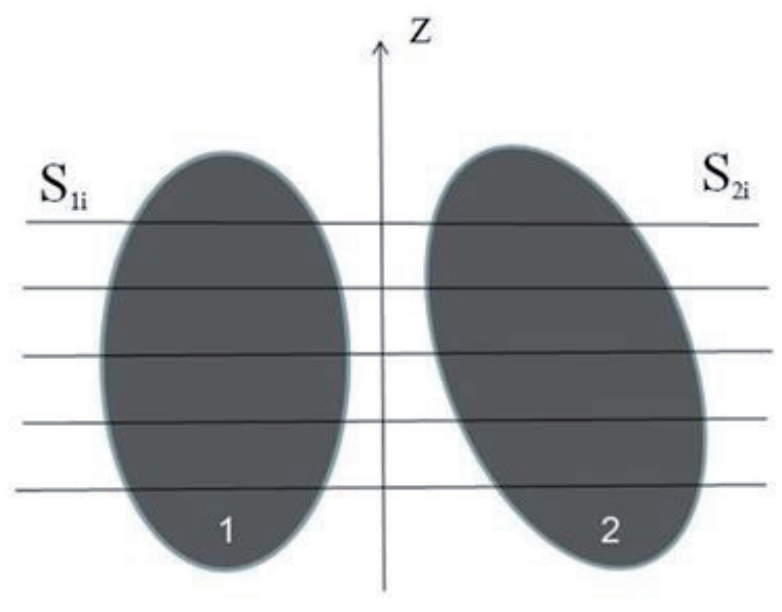

Рис. 1. К обоснованию принципа Кавальери.

Несмотря на очевидность указанного противоречия, к тому же рассмотренного в работах $[6,7]$, метод прочно вошёл в практику из-за кажущейся простоты и непрерывно автоматизировался [8-12] вплоть до применения современных компьютеров для анализа изображений шлифа. Список параметров, характеризующих сечения минеральных зёрен, и быстрота обработки статистик выросли многократно. Но в части восстановлений истинных метрических характеристик минеральных зёрен по таковым их плоских (тем более линейных) сечений идеология остаётся прежней. Компании, производящие автоматические анализаторы структур, предлагают пакеты программ без обсуждения проблемы. Более того, даже анализ двумерных изображений не использует доступные разделы математики. Так, расстояние между минеральными зёрнами в шлифе подменяется евклидовым расстоянием между точками, взятыми в пределах зёрен, тогда как есть более сложная, но легко программируемая метрика Ф. Хаусдорфа, позволяющая делать это корректно.

Качественно новое направление исследований - стереологическая реконструкция - возникло из очевидного наблюдения, что произвольное сечение сферической формы всегда меньше её характерного сечения (рис. 2, слева). Но из этого следует, что объёмная доля такой минеральной фазы в горной породе и руде, приравненная к доле её плоских сечений, всегда занижена за счёт вмещающей матрицы. Соответствующая общая задача - отыскание распределения истинных размеров частиц по распределению размеров их случайных сечений - относится к классу обратных задач, ти- 


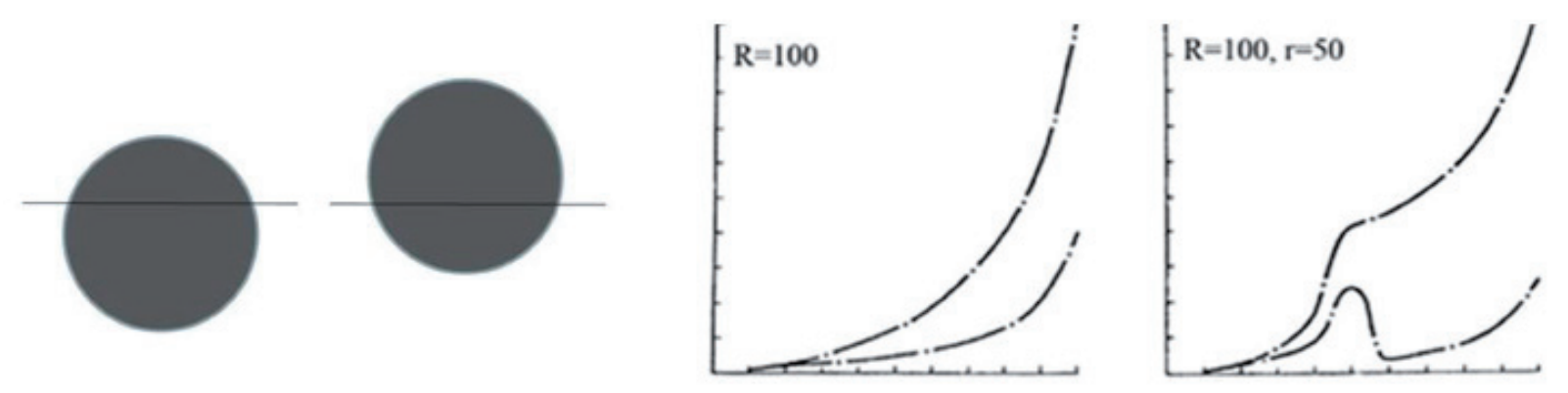

Рис. 2. Слева: размер сечения выпуклого зерна всегда меньше характерного, в модальном анализе его объёмная доля занижена. Справа: к распознаванию истинных размеров сферических частиц по размерам круговых сечений; $\mathrm{R}=100$ - частицы радиусом 100 условных единиц; $\mathrm{R}=100, \mathrm{r}=50$ - два набора частиц одного вида, неразличимых в сечениях (например, две генерации одного минерала); горизонтальная шкала - радиусы сечений от 0 до 100 разбиты на 10 классов; вертикальная шкала - частоты сечений по классам (нижние кривые) и накопленные частоты (верхние кривые).

пичных в геофизике, и аналитически решена лишь для сферических и эллипсоидальных частиц благодаря относительно простому аналитическому описанию этих форм [13, 14]. Но даже в этом случае практическое использование теории требует подбора наилучшего решения и оценки погрешностей (рис. 2, справа). Для более сложных форм минеральных зёрен не обойтись без математического моделирования на мощных компьютерах. Историю развития этого направления можно почерпнуть из следующего далеко не полного списка работ [15-20].

Таким образом, из-за чрезвычайного разнообразия форм минеральных зёрен в горных породах и рудах методы стереологической реконструкции приводят к интегральным уравнениям с аналитически трудно задаваемым фактором формы. Практическое применение теории тонет в подборе наилучшего решения обратной задачи и сложных оценках погрешностей измерений. На смену модальному анализу горных пород и руд в шлифах должны прийти методы рентгеновской (или иной) томографии. Стандартизация модального анализа горных пород и руд в шлифах путём создания их искусственных аналогов с заведомо известными объёмными долями минеральных зёрен и широким спектром петрографических структур может служить межлабораторному сравнению точности метода, но не решит его проблем по существу.

Работа выполнена в рамках темы НИР ГИ КНЦ РАН № 0231-2015-0001.

\section{Литература}

1. Delesse M. Procede mecanique pour determiner la composition des roches // Annales des mines. De memoires sur l'exploitation des mines. Quatrieme serie. T. XIII. Paris: Carilian-Goeury et Dalmont, 1848. P. 379-388.

2. Rosiwal A. Über geometrische Gesteinanalysen. Ein einfacher Weg zur ziffermässigen Feststellung des Quantitätsverhältnisses der Mineralbestandtheile gemengter Gesteine // Verhandlungen der keiserlichköniglichen Geologischen Reichsanstalt. Wien: Verlag der keiserlich-königlichen Geologischen Reichsanstalt, 1898. S. 143-175.

3. Глаголев А.А. Количественный минералогический анализ горных пород под микроскопом. Л.: Госгеолиздат, 1932. $25 \mathrm{c}$.

4. Глаголев А.А. О геометрических методах количественного минералогического анализа горных пород. М.-Л.: Госгеолиздат, $1933.47 \mathrm{c.}$

5. Глаголев А.А. Геометрические методы количественного анализа агрегатов под микроскопом. М.-Л.: Госгеолиздат, 1941. $263 \mathrm{c}$.

6. Чейз Ф. Количественно-минералогический анализ шлифов под микроскопом. М.: Иностранная литература, 1963. $156 \mathrm{c}$.

7. Krumbein W.C. Thin-section mechanical analysis of indurated sediments // Journal of Geology. 1935. V. 43. P. 482-496. 
8. Shand S.J. A recording micrometer for geometrical rock analysis // Journal of Geology. 1916. V. 24. P. $394-404$.

9. Wentworth C.K. An improved recording micrometer for rock analysis // Journal of Geology. 1923. V. 31. P. 228-232.

10. Hunt W.F. An improved Wentworth recording micrometer// American Mineralogist. 1924. V. 9. P. $190-193$.

11. Dollar A.T.J. An integrating micrometer for the geometrical analysis of rocks // Mineralogical Magazine. 1937. V. 24. P. 577-594.

12. Hurlbut C.S., Jr. An electric counter for thin-section analysis // American Journal of Science. 1939. V. 237. P. 253-261.

13. Wicksel S.D. The corpuscle problem. A mathematical study of a biometric problem // Biometrica. 1925. V. 17. P. 84-99.

14. Wicksel S.D. The corpuscle problem. $2^{\text {nd }}$ memoir. Case of ellipsoidal corpuscles // Biometrica. 1926. V. 18. P. 151-172.

15. Журавский А.М. Минералогический анализ шлифа с точки зрения вероятностей. М.-Л.: Госгеолиздат, 1932. 20 c.

16. Шванов В.Н., Марков А.Б. Гранулометрический анализ песчаников в шлифах // Геология и разведка. 1960. № 12. C. 49-55.

17. Иванов Н.В. Новое направление в опробовании рудных месторождений. М.: Госгеолиздат, 1963.179 с.

18. Чернявский К.С. Стереология в металловедении. М.: Металлургия, 1977. 375 с.

19. Иванов О.П., Ермаков С.Ф., Кузнецова В.Н. Повышение точности определения весового гранулометрического состава рудных минералов по измерениям в шлифах // Труды ЦНИИ олово. Н.: Наука, 1979. С. 10-14.

20. Гульбин Ю.Л. О стереологических реконструкциях размеров зёрен в агрегатах // Записки Российского минералогического общества. 2004. № 4. С. 71-91. 